\title{
Addressing the Long-Term Care Crisis: Identifying Opportunities for Improvement Using Rapid Reviews
}

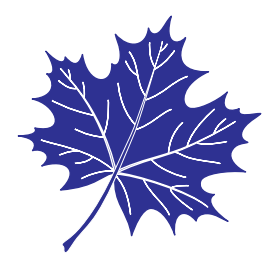

Rae R.A. Petrucha, MD ${ }^{1}$, Elizabeth G. Hansen, BSc Hon ${ }^{2}$, Lindsay D. Ironside, BSc ${ }^{2}$, Olivia J.M. Lafrance, BSc Hon $^{2}$, Rhonda D.T. Bryce, MD ${ }^{1}$, Nicole A. Jacobson, MA ${ }^{1}$, Vivian R. Ramsden, PhD, MCFP (Hon) ${ }^{1}$

${ }^{1}$ Department of Academic Family Medicine, University of Saskatchewan; ${ }^{2}$ College of Medicine, University of Saskatchewan, Saskatoon, $S K$

https://doi.org/10.5770/cgj.25.535

\section{ABSTRACT}

\section{Background}

Long-term care (LTC) facilities require urgent, evidencebased care renewal. During 2020 three medical student-driven research projects aiming to study care satisfaction, patient care team dynamics, and advance care directive effectiveness in a local LTC facility required a marked shift in approach due to COVID-19 regulations.

\section{Methods}

All three projects were re-invented as rapid reviews from their initial designs intended to provide a baseline for quality improvement projects. English-limited PubMed searches for publications within the past 10 years were undertaken. Review articles were prioritized and supplemented by individual studies. Students reviewed the initial abstracts, reviewed them with a supervisor/mentor, assessed the articles for quality, and synthesized major themes.

\section{Results}

A total of 52 publications were evaluated for the final synthesis of all three projects. Relevant information was retrieved for all three areas, suitable for local evaluation/intervention at micro, meso, and macro policy levels.

\section{Conclusions}

Rapid reviews of issue-specific, long-term care literature are low resource avenues towards coordinated care improvement. They may also serve as rapid means for regular policy updates while providing next-generation care providers with improved LTC perspectives.

Key words: long-term care, patient-centred care, patient satisfaction, quality of life, patient care team, advance care planning, rapid review, medical students

\section{INTRODUCTION}

In spite of an ageing Canadian population, long-term care (LTC) reform has been ignored for decades ${ }^{(1,2)}$ to unquestionable detriment. ${ }^{(3)}$ Generation of relevant knowledge and its translation into policy at macro, meso, and micro levels has never been of greater priority. ${ }^{(4)}$

In 2020, the research team anticipated completing three separate projects as part of the Dean's Summer Student Research Program, College of Medicine, University of Saskatchewan. All three were viewed as initial phases of larger practice improvement projects and were directed toward developing an understanding of multiple areas of interest within a single urban-Canadian LTC facility. With the advent of COVID-19, all three projects required adaptation to the rigorous research safety criteria set out by the College of Medicine and the University of Saskatchewan. This context created a conundrum: How could similar relevant knowledge be generated under these constrained conditions that would provide foundational information for the LTC facility while building research skills with the undergraduate medical students during the proposed ten-week research experience?

A rapid review is "a form of knowledge synthesis that accelerates the process of conducting a systematic review through streamlining or omitting a variety of methods to produce evidence for stakeholders in a resource-efficient manner."(5) Rapid reviews are frequently used in decisionmaking and/or policy development, although predominantly concerned with urgent and focused concerns (e.g., interventions, clinical outcomes, specific exposures) of specific stakeholders, ${ }^{(6)}$ rather than long-term policy. Furthermore, their use in summarizing qualitative literature has been less well defined, ${ }^{(7)}$ and our preliminary search of PubMed suggests they have been infrequently used to address LTC questions. Thus, this manuscript will set out the method used in three student-driven rapid reviews that aimed to support improved practices related to overall patient and family satisfaction in 
LTC, improved LTC team dynamics, and patient-optimized advanced care directives within a single LTC facility. The three specific questions to be answered were:

1. What are the strengths and opportunities for change within long-term care facilities?

2. What is the current evidence for team-based strategies to assist LTC administrative leaders and health-care providers in improving patient-centred care?

3. What evidence and best practices go into co-creating advance care directives that are meaningful to individuals living in long-term care facilities and their families?

\section{METHODS}

In addressing the need for an appropriate methodology, approaches to rapid reviews were sought from white and gray literature. Among the resources found, "The Rapid Review Guidebook, steps for conducting a rapid review" (8) was deemed to have the most appropriate level of directional clarity and detail for student work. A project template, previously developed for the Department of Academic Family Medicine's Residency Program, was adapted to incorporate the steps outlined in the Guidebook. As two of the literature searches of the PubMed database had already been completed prior to the COVID-19 pivot to rapid reviews, one additional search was undertaken. Due to limited initial findings, one search was supplemented with a broader second search.

Additional preparatory steps were undertaken prior to student engagement. For each project, virtual information repositories (OneDrive files), accessible to the supporting team and the specific student, were set up to allow easy access to project-specific resources and the sharing of new documents as they became available. Resource materials (i.e., initial rapid review resource documents, literature lists/abstracts from the searches, other relevant literature, and the project template) were stored there. Roles were defined early in the project, with the primary supervisor continuing to act as the official supervisor, clinical expert, and facility representative (RP), while members of the research team (RP, RB, VR, and $\mathrm{NJ}$ ), respectively, undertook responsibilities related to methodology, student support, administration, and information. A weekly online meeting time was established to ensure regular communication and interpersonal connection, and a preliminary timeline was proposed to encourage timely arrival at project milestones.

Students were introduced to the project template early in the process and encouraged to progressively complete it from the outset. To become contextually familiar, they completed the background section entitled "Current Knowledge", utilizing previous resources and their own search of the white and grey literature. The students also engaged in the application for an Exemption from Ethical Review, which was granted by the University of Saskatchewan's Behavioural Research Ethics Board for all three projects. The students then began by reviewing the literature searches, prioritizing the titles and abstracts most relevant to the search terms and omitting ones they viewed as non-contributory to their particular study question. As review articles were prioritized, this process started with the review articles and included single studies as time permitted. All of the review article abstracts not included and ten per cent of the single studies not included were reviewed by the supervisor (RP) to ensure that their removal was appropriate. The remaining literature was further limited to include only studies in English published in the past 10 years. The quality of the studies was assessed by the student using the Critical Appraisal Skills Program checklists, ${ }^{(9)}$ with ten per cent of these assessments reviewed by a mentor (RB or VR). Findings were thematically summarized in a draft manuscript and presented in abstract/poster format. ${ }^{(10-12)}$

Supportive contextual dynamics, present across all of the above steps, included standing weekly team meetings, fixed daily virtual drop-in "office hours", and immediate availability of the supervisor by text for questions. The College of Medicine also provided educational sessions for the students regarding poster creation and presentation.

\section{RESULTS}

The three reviews generated three sets of interconnected principles/recommendations relevant to LTC. Review process outcomes are presented in Table 1, and findings are summarized for each project below.

\section{Strengths and Opportunities for Change Within Long-Term Care Facilities}

A. Residents should be encouraged to make decisions about their life and care. Autonomy in LTC homes is important to maintain residents' satisfaction and quality of life. Patient-centred care is key to autonomy at all stages of the LTC experience ${ }^{(13)}$ and across multiple facets (e.g., self-care routines, ${ }^{(14)}$ sleep schedules, ${ }^{(15)}$ dining, ${ }^{(16)}$ decision-making processes $\left.{ }^{(17)}\right)$. Physical environments may contribute to this. ${ }^{(16,18-20)}$

B. Personal relationships between staff and residents facilitate care that is unique and resident-specific. Relationships between the residents and LTC workers significantly impact residents' experience in LTC homes. Residents' preferences regarding the staff and avenues to improve staff-resident relationships, including key relational dynamics (e.g., sensitivity, ${ }^{(21)}$ active listening, ${ }^{(21)}$ encouragement ${ }^{(22)}$ ) have been described. Staff members should be trained in patient-centred care strategies. ${ }^{(23)}$ Communication between staff as to how individualized care is best delivered to specific residents is necessary for consistent care. ${ }^{(24)}$

C. Opportunities for social engagement as well as mentally stimulating activities should be provided. Social engagement is an important factor in residents' quality of life, 
PETRUCHA: RAPID REVIEWS IN LONG-TERM CARE

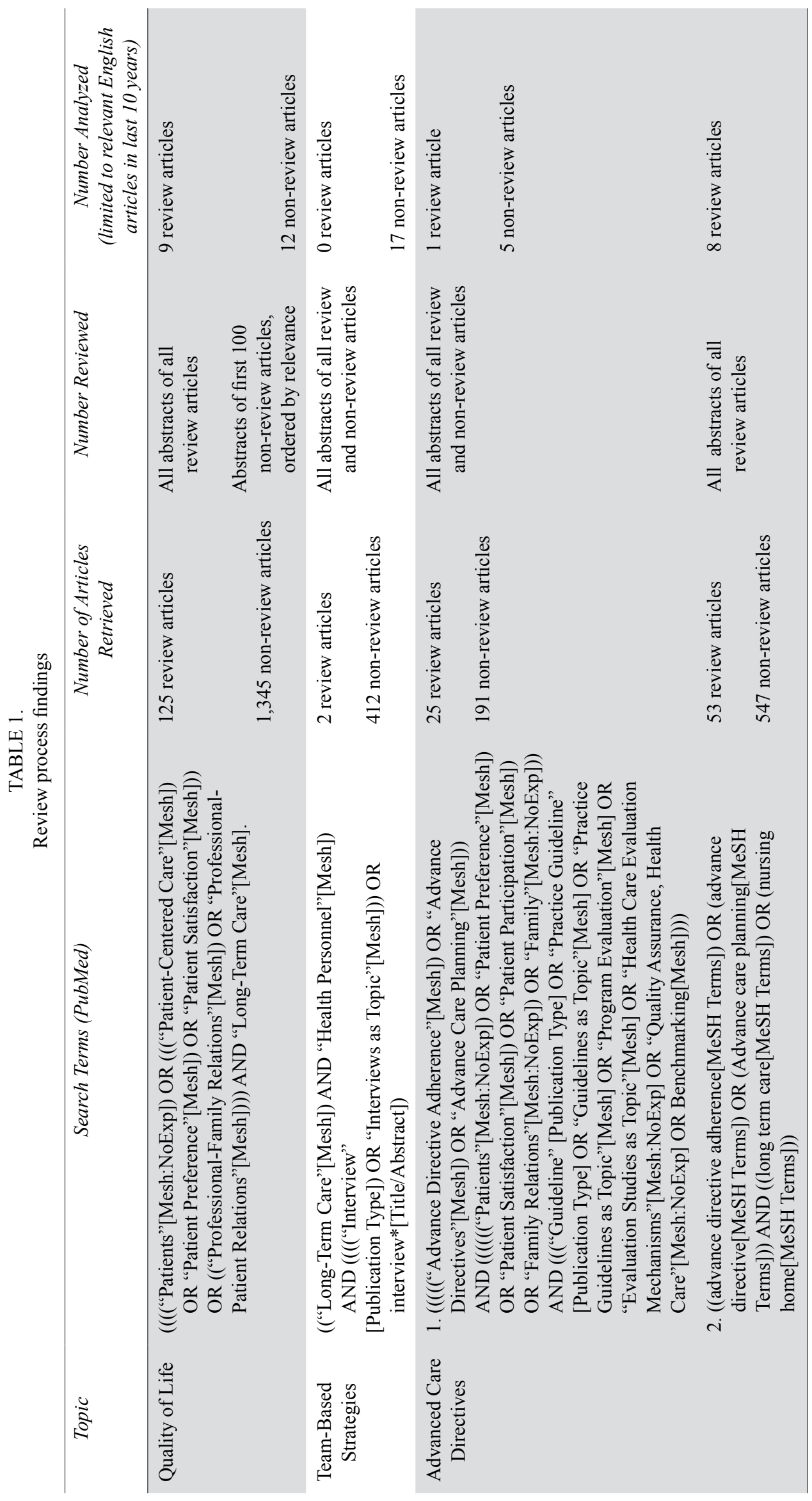


physical/mental health, and well-being. ${ }^{(21,25)}$ Maintaining regular contact with family and friends, and the option of their inclusion in care, have been recognized as top priorities. ${ }^{(14)}$ Additionally, mentally stimulating activities (reading, keeping up with the news, playing music, internet access, radio, television, and storytelling) are important to residents. ${ }^{(14,25)}$

D. Home-like physical environments provide residents with social interactions, mental stimulation, and access to the outdoors. The physical environment of LTC facilities plays an important role in residents' quality of life. Small-scale, home-like settings and décor, in contrast to an institutional design, are appreciated and promote social interaction, ${ }^{(18,21)}$ positively impacting residents with dementia. ${ }^{(19,20)}$

E. Dining experiences offer multi-faceted opportunities for improved well-being. As above, homelike décor is also comforting in the dining area. ${ }^{(16)}$ Family-style meals result in increased energy intake, ${ }^{(18)}$ improved quality of life, ${ }^{(25)}$ and feelings of social support. ${ }^{(25)}$ Right-angle seating, ${ }^{(18)}$ small group seating, ${ }^{(18)}$ kitchen accessibility, ${ }^{(16)}$ and participation in mealtime serving ${ }^{(25)}$ support social interaction, independence, autonomy, and quality of life. Optimizing lighting, noise levels, and visual contrast have been found to reduce mealtime stress, increase intake, and maximize functional independence in dementia patients. ${ }^{(18)}$

F. Residents living in long-term care prefer smaller facilities. Having a fewer number of residents provides more privacy. ${ }^{(25)}$ For residents with dementia, privacy is particularly important when eating to avoid the potentially overwhelming stimulus of communal meals. ${ }^{(18)}$ When bathing, privacy also reduces agitation. ${ }^{(19)}$ Residents should also be given privacy when toileting and only be assisted when necessary. ${ }^{(14)}$

\section{Team-Based Strategies for Improving Patient- Centered Care}

A. Communication effectiveness should be maximized. Implementation of electronic health records within LTC facilities has been found to improve legibility, consistency, accuracy, accessibility, and quality of the records, increasing speed of care and reducing errors due to misconceptions. ${ }^{(26,27)}$ The integration of a higher educated team member, such as a nurse practitioner, was also found to improve communication and collaboration between allied health professionals within the LTC setting. ${ }^{(28,29)}$

B. Change should be strategically implemented. The most successful changes within LTC promote teamwork and highlight the resident benefits of the initiative. ${ }^{(30,31)}$ Interactive workshops/meetings that provide interdisciplinary connection strengthen personal staff relationships and unity; ${ }^{(30,32)}$ follow-up meetings that clarify and refresh the change process as it unfolds are sustaining. ${ }^{(30,31)}$ Strategic reminders are effective in promotion, ${ }^{(31)}$ as is the identification of a change champion, a peer with new protocol expertise who takes responsibility for implementation. $(30,33)$ A slow phase-in approach may offset negativity about change while allowing barriers discovered during implementation to be addressed. ${ }^{(33)}$

C. Engaged management is impactful. LTC facilities with continuity of front-line care, including leaders who help the direct care staff as part of the team, result in better teamwork and happier workers. ${ }^{(30,34)}$ Successful leaders trust direct care workers, ${ }^{(34)}$ value their opinions, ${ }^{(28)}$ and provide positive recognition consistently. ${ }^{(34)}$ Leaders who are flexible and encouraging, who appreciate initiative/ problem solving, and who respect autonomy have more successful LTC facilities. ${ }^{(30,34)}$ Fluidity in supervisors'/ direct care workers' roles with the sharing of certain tasks fosters effective teamwork relationships, ${ }^{(34)}$ whereas discipline-focused approaches, lack of worker influence on decisions, and limited positive feedback hallmark low teamwork facilities. ${ }^{(35)}$

D. Family members are valuable team members. Family expertise can improve care quality, but family may require guidance on appropriate ways to contribute. LTC staff struggle when family members are perceived as difficult to work with or become involved inappropriately. ${ }^{(36)}$ Other times, staff feel families are not involved enough, necessitating excessive socio-emotional staff care. ${ }^{(36)}$ Many LTC staff believe family should have at least a minimal amount of involvement with their resident. ${ }^{(36)}$

LTC facilities that successfully include family encourage decision-making involvement, communicate consistently about care/care rationale, ${ }^{(36,37)}$ and actively seek families' perspectives. ${ }^{(37)}$ Punitive actions when questions, concerns, or opinions are voiced lead to discomfort and inability to contribute. ${ }^{(36)}$ Staff often have limited time to engage meaningfully with residents and their families during daily routines; thus, improvements in understaffing, decreasing staff turnover, and increasing interactive social events for family members, residents, and staff have been suggested to improve relationships. ${ }^{(36,37)}$

\section{Resident and Family Preferences for Advanced Care Planning (ACP)}

A. ACP should be viewed positively and personally. Generally, older people welcome ACP. ${ }^{(38,39)}$ Both family and residents agree that ACP should occur at the "right time", but timing opinions vary. ${ }^{(39)}$ Reluctance may arise from deference to others, ${ }^{(40)}$ unwillingness to plan, ${ }^{(40)}$ personal unpreparedness, ${ }^{(40)}$ or avoidance of dying considerations. (39) Some residents believe medical decisions are strictly physician-driven, although few residents desire sole responsibility. ${ }^{(39)}$ Resident attitudes towards ACP are influenced by the need to "put affairs in order"; medical, living, or financial issues of friends/family members; 
previous death and dying experiences; and concern for family member burdens. ${ }^{(39)}$ Residents generally value quality of life, natural death, and pain relief. ${ }^{(39)}$

B. Family members should be engaged in ACP. Although family members are generally willing to engage, ${ }^{(39)} \mathrm{ACP}$ may induce feelings of guilt, failure, denial, or refusal to "give up". ${ }^{(40)}$ Family members, in assuming the substitute decision-maker role when decisions are unavoidable, often experience conflict. ${ }^{(41)}$ Although advance directives are a main information source, discussion with relatives, the patient's previously expressed wishes, other patientdriven decisions, and other aspects of the patient's life are often considered. ${ }^{(41)}$ Decision-making is impacted by the family's understanding of the relative's condition, quality of life, values, and beliefs. ${ }^{(41)}$ Even when aware of their relative's wishes, a substitute's decisions may differ, ${ }^{(41)}$ although physician opinions are highly valued. ${ }^{(42)}$ Inadequate communication between residents, relatives, and practitioners impedes clear decision-making. ${ }^{(39)}$

C. ACP should be undertaken among persons with dementia as early as possible. As decision-making capacity of persons with dementia is limited and their care needs progressive, early ACP is beneficial. ${ }^{(38,41)}$ Conversations near admission, when communicative and cognitive capacity may be sufficient, are ideal. ${ }^{(43)}$ When offered opportunities to express their thoughts regarding future care, many individuals with dementia are able to respond consistently. ${ }^{(39)}$ Early in-depth meetings can establish and/or support the resident's and family's dementia knowledge, ${ }^{(40,41)}$ the need for and comfort with $\mathrm{ACP},{ }^{(39,41,44)}$ effective family dynamics, ${ }^{(40)}$ and preferences for future communication. ${ }^{(41)}$ Most families are not educated on the terminal nature of dementia and are relieved to have information for future preparations. ${ }^{(44)}$

D. ACP should be an organizational priority. Supportive organizational management facilitates ACP. ${ }^{(43,45)}$ Limited time and inadequate resources are major barriers to ACP implementation. ${ }^{(40,43,45,46)}$ Delegating ACP responsibilities to specific staff within a hierarchical organization limits integration, ${ }^{(40,45)}$ while interdisciplinary, cross-level involvement facilitates ACP. ${ }^{(40,43)}$ A centralized, standardized, clearly documented process is also helpful. ${ }^{(40,44,47)}$ Health-care practitioners within the facility must be trained to initiate and facilitate ACP, and support for related professional development may be needed. ${ }^{(39,44)}$ Exemplifying this, care providers are often uncomfortable with both the emotional nature of ACP and the legal aspects of advance directives. ${ }^{(40,44)}$ Physician non-attendance ${ }^{(44)}$ and a lack of trust between residents, family, and staff ${ }^{(40,41)}$ are additional barriers.

E. Additional ACP strategies may be considered. Several literature-based interventions may mitigate $\mathrm{ACP}$ barriers. Lay people have been found to acceptably and effectively facilitate $\mathrm{ACP},{ }^{(47)}$ and scalable systems for such training already exist. ${ }^{(48)}$ A patient-editable, electronic decision aid linked to an electronic health record has been found to improve $\mathrm{ACP}$ uptake and quality, although this requires LTC assessment. ${ }^{(45)}$ Another decision aid replacing ACP has been found to have good agreement with physician decisions. ${ }^{(49)}$ Video documentation of advance directives within hospital has been appreciated by patients but is insufficient for ACP. ${ }^{(50)}$

\section{DISCUSSION}

The knowledge generated by this set of rapid reviews is twofold. The research group was able to redirect the projects to a COVID-compliant, resource non-intensive approach that exposed multiple learners to the research process and resulted in the development of multiple evidence-based insights appropriate for clinical practice consideration in the facility.

This group of projects developed and utilized a project template (available on request) that could be applied easily in health services systems, specific facilities, or by individual practitioners performing a rapid review. Considering the current focus on LTC nationally and internationally, and the need to address multiple issues in these facilities, having tools that allow for a non-resource-intensive approach to addressing the issues will be important. The research team also developed processes that could be applicable to practitioners working in an academic setting, supervising research, or working on quality improvement projects with medical learners. Processes that allow for meaningful research/quality improvement among learners, while still meeting safety criteria in the setting of a pandemic, have particular relevance for current and future environments.

This set of rapid reviews provided the opportunity for skill development by the medical learners, even with a significant pivot in methodology, and allowed for their engagement despite the complete inaccessibility of the actual facility due to COVID-19 pandemic policies. These projects also provided the students an opportunity to develop a more sophisticated lens through which to view their experiences with LTC as they progress through the remainder of their medical training.

The recommendations generated can be organized into categories based on the level at which they can be applied: micro, meso, and macro. At the micro level, individual practice change for many different health-care team members is possible and may be implemented quickly with few-to-no additional resources required. At the meso level, changes can be implemented at the facility by local administration and team members and, as such, may require more time and resources to implement. Changes at the macro level, implemented by a Health Authority or Provincial Ministry of Health, would likely take the longest amount of time and require significant resources. Table 2 shows which recommendations fall into each of these three categories.

The authors recognize multiple important limitations that affect this work. Although there is considerable variability in rapid review methodology, ${ }^{(51)}$ rapid reviews generally utilize 
TABLE 2.

Recommendations at the micro, meso, and macro levels

\begin{tabular}{lcc}
\hline \multicolumn{1}{c}{ Micro } & Meso & Macro \\
\hline $\begin{array}{l}\text { Residents should be empowered to make } \\
\text { decisions about their life and care. }\end{array}$ & $\begin{array}{c}\text { Provide opportunities for social engagement, as well } \\
\text { as mentally stimulating activities. }\end{array}$ & $\begin{array}{c}\text { Residents should be given } \\
\text { appropriate amounts of } \\
\text { privacy and opportunities } \\
\text { for alone time. }\end{array}$ \\
$\begin{array}{l}\text { The staff should develop personal } \\
\text { relationships with the residents to provide } \\
\text { care that is unique and resident-specific. }\end{array}$ & $\begin{array}{c}\text { The physical environment should be home-like and } \\
\text { provide residents with social interactions, mental } \\
\text { stimulation, and access to the outdoors. }\end{array}$ & $\begin{array}{c}\text { Communication effectiveness } \\
\text { should be maximized. }\end{array}$ \\
$\begin{array}{l}\text { ACP should be viewed positively and } \\
\text { personally. }\end{array}$ & $\begin{array}{c}\text { The dining environment should be person-centred, } \\
\text { home-like, and optimize sensory stimulation for } \\
\text { patients with dementia. }\end{array}$ & $\begin{array}{c}\text { Additional ACP strategies may } \\
\text { be considered. }\end{array}$ \\
$\begin{array}{l}\text { Family members should be engaged in ACP. } \\
\text { ACP should be undertaken among persons } \\
\text { with dementia as early as possible. }\end{array}$ & Change should be strategically implemented. & Engaged management is impactful. \\
\hline
\end{tabular}

at least two literature sources. ${ }^{(51-53)}$ Our use of MeSH terms may have missed more recent articles that had not yet been indexed. In facilitating the short timeline, the single-reviewer approach, focus on published literature, language limitation, and ten-year time period may also have restricted findings. The ten-week project period did not allow all single studies to be reviewed. For two of the three projects, the searches themselves had been designed to specifically support the initially planned in-person, qualitative projects; as such, more quantitative publications may have been missed.

There are additional high priority LTC areas that were not addressed in this manuscript due to the limited scope of the originally planned summer student research projects. These include needs and strategies related to palliative care and End of Life care provided within LTC. This area is important due to the substantial percentage of residents who die annually within LTC facilities, ${ }^{(54)}$ highlighted by the recently increased mortality within these settings due to COVID-19. ${ }^{(55)}$ The team did not evaluate the literature for specific Goals of Care which are highly reliant on quality ACP, as the initially planned project evaluating ACP was focused on patient/family priorities and preferences for ACP documents rather than specific care options. There was only a brief mention of workforce complement in the results section, where understaffing and staff turnover were recognized as impacting quality of care. As outcomes within LTC facilities that were heavily impacted by the COVID-19 pandemic have shown, ${ }^{(3)}$ staffing appropriateness is an area requiring much urgent attention so as to improve care and workforce stability within LTC facilities. (56) As our literature review focused on effective teamwork strategies rather than maximizing the effectiveness of specific staff roles, it is likely that existing literature related to this aspect was not captured in the review.

\section{CONCLUSION}

The above recommendations and their applicability to practice and policy change within the LTC setting have provided a great deal of valuable information to share with the original facility in spite of the aforementioned limitations. The initial plan - to discover three distinct, area-specific baselines from which to initiate a quality improvement program within the facility - was not possible due to pandemic restrictions. Yet all three projects were able to pivot to a basic rapid review format that, instead, generated a deeper understanding of related literature. This information will better inform the design and methodology of next steps in conducting quality improvement projects within the LTC facility. Their simultaneous undertaking across multiple aspects of LTC has potential to result in more integrated, coordinated initiatives.

Although the three projects outlined in this paper were completed on a very tight timeline, this practical application of rapid review methodology not only provided immediate evidence-based points of evaluation within our LTC setting but may also serve as a feasible approach to long-term policy maintenance via regular updates. It is expected that LTC will have new priority in Canadian society; thus, we propose that the rapid review methodology can be a valuable, accessible tool for identifying new related knowledge, stimulating critical evaluation, and ensuring that practice improvement is top-of-mind across multiple aspects of LTC.

\section{ACKNOWLEDGEMENTS}

We acknowledge the support of the Department of Academic Family Medicine, College of Medicine, University of Saskatchewan in this work. 


\section{CONFLICT OF INTEREST DISCLOSURES}

We have read and understood the Canadian Geriatrics Journal's policy on conflicts of interest disclosure and declare there are no conflicts of interest to report.

\section{FUNDING}

This work was financially supported by the Dean's Summer Research Projects Program, Office of the Vice-Dean of Research, College of Medicine, University of Saskatchewan. Elizabeth G. Hansen and Olivia J.M. Lafrance received additional funding from the Saskatchewan Centre for PatientOriented Research (SCPOR).

\section{REFERENCES}

1. Banerjee A. An overview of long-term care in Canada and selected provinces and territories [Internet]. Toronto $(\mathrm{ON})$ : Women and Health Care Reform Group; 2009 [cited $2021 \mathrm{Feb}$ 28]. Available from: https://www.researchgate.net/publication/284652528_Long-term_care_in_Canada_An_overview

2. Twomey A. The marginalization of long-term care in Canadian federal policy making [Internet]. Kingston, ON: Queens University; 2013 [cited 2022 Jan 27]. 19 p. Available from: https://web.archive.org/web/20180127134004/https://www. queensu.ca/sps/qpr/sites/webpublish.queensu.ca.qprwww/files/ files $/ 10 \% 20$ marginalization $\% 201$ ong $\% 20$ term $\% 20$ care.pdf

3. Mialkowski CJJ. Operation LASER - Joint Task Force Central observations in long term care facilities in Ontario [Internet]. Toronto (ON): Canadian Armed Forces; 2020 May 20 [cited 2021 Jan 14]. Available from: https://assets.documentcloud. org/documents/6928480/OP-LASER-JTFC-Observations-inLTCF-in-On.pdf

4. MacDonald B, Wofson M, Hirdes JP. The future co\$t of long-term care in Canada [Internet]. Toronto, ON: National Institute on Ageing; 2019 Oct [cited 2021 Jan 14]. 45 p. Available from: https://static1.squarespace.com/ static/5c2fa7b03917eed9b5a436d8/t/5d9ddfbb353e453a7a90 800b/1570627515997/The\%2BFuture\%2BCost_FINAL.pdf

5. Hamel C, Michaud A, Thuku M, et al. Defining rapid reviews: a systematic scoping review and thematic analysis of definitions and defining characteristics of rapid reviews. J Clin Epidemiol [Internet]. 2021 Jan;129:74-85. Available from: https://pubmed. ncbi.nlm.nih.gov/33038541/

6. Hartling L, Guise JM, Kato E, et al. A taxonomy of rapid reviews links report types and methods to specific decision-making contexts. J Clin Epidemiol [Internet]. 2015 Dec;68(12):1451-62. e3. Available from: https://pubmed.ncbi.nlm.nih.gov/26278023/

7. Campbell F, Weeks L, Booth A, Kaunelis D, Smith A. A scoping review found increasing examples of rapid qualitative evidence syntheses and no methodological guidance. J Clin Epidemiol [Internet]. 2019 Nov;115:160-71. Available from: https://pubmed.ncbi.nlm.nih.gov/31229582/

8. Dobbins M. Rapid Review Guidebook: Steps for conducting a rapid review [Internet]. Hamilton, ON: The National Collaborating Centre for Methods \& Tools (NCCMT); 2017 [cited 2020 Mar 27]. 26 p. Available from: https://www.nccmt.ca/uploads/ media/media/0001/02/800fe34eaedbad09edf80ad5081b9291a cf1c0c2.pdf
9. Critical Appraisal Skills Programme (2019). CASP checklists [Internet]. Oxford (UK); c2019 [cited 2020 June 19]. Available from: https://casp-uk.net/casp-tools-checklists/

10. Lafrance $\mathrm{O}$, Petrucha R, Bryce R, et al. The strengths and opportunities for change related to care of individuals in long term care settings and their families. Poster session presented at: Undergraduate Research Showcase, College of Medicine, University of Saskatchewan [Internet]; 2020 Oct 21.

11. Ironside $\mathrm{L}$, Petrucha $\mathrm{R}$, Bryce $\mathrm{R}$, et al. What strategies in the literature improve team-based patient-centered care in long term care settings? Poster session presented at: Undergraduate Research Showcase, College of Medicine, University of Saskatchewan [Internet]; 2020 Oct 21.

12. Hansen E, Petrucha R, Bryce R, et al. Goals of care and advance care directives in the long-term care setting; patient preferences and tools for best practice. Poster session presented at: Undergraduate Research Showcase, College of Medicine, University of Saskatchewan [Internet]; 2020 Oct 21.

13. Sullivan GJ, Williams C. Older adult transitions into long-term care: a meta-synthesis. J Gerontol Nurs [Internet]. 2017 Mar 1;43(3):41-49. Available from: https://pubmed.ncbi.nlm.nih. gov/27845805/

14. Abbott KM, Klumpp R, Leser KA, Straker JK, Gannod GC, Van Haitsma K. Delivering person-centered care: important preferences for recipients of long-term services and supports. $J$ Am Med Dir Assoc [Internet]. 2018 Feb;19(2):169-73. Available from: https://pubmed.ncbi.nlm.nih.gov/29146223/

15. Harrison J, Frampton S. Resident-centered care in 10 U.S. nursing homes: residents' perspectives. J Nurs Scholarsh [Internet]. 2017 Jan;49(1):6-14. Available from: https://pubmed.ncbi.nlm. nih.gov/27676137/

16. Hung L, Chaudhury H, Rust $T$. The effect of dining room physical environmental renovations on person-centered care practice and residents' dining experiences in long-term care facilities. $J$ Appl Gerontol [Internet]. 2016 Dec;35(12):1279-1301. Available from: https://pubmed.ncbi.nlm.nih.gov/25724947/

17. Bangerter LR, Van Haitsma K, Heid AR, Abbott K. "Make me feel at ease and at home": differential care preferences of nursing home residents. Gerontologist [Internet]. 2016 Aug;56(4):702-13. Available from: https://pubmed.ncbi.nlm. nih.gov/26035895/

18. Chaudhury H, Hung L, Badger M. The role of physical environment in supporting person-centered dining in long-term care: a review of the literature. Am J Alzheimers Dis Other Demen [Internet]. 2013 Aug;28(5):491-500. Available from: https:// pubmed.ncbi.nlm.nih.gov/23687182/

19. Chaudhury H, Cooke HA, Cowie H, Razaghi L. The influence of the physical environment on residents with dementia in long-term care settings: a review of the empirical literature. Gerontologist [Internet]. 2018 Sep 14;58(5):e325-e337. Available from: https://pubmed.ncbi.nlm.nih.gov/28329827/

20. Ausserhofer D, Deschodt M, De Geest S, et al. "There's no place like home": a scoping review on the impact of homelike residential care models on resident-, family-, and staffrelated outcomes. J Am Med Dir Assoc [Internet]. 2016 Aug 1;17(8):685-93. Available from: https://pubmed.ncbi.nlm.nih. gov/27130574/

21. Behrens LL, McGhan G, Abbott KM, et al. Mapping core concepts of person-centered care in long-term services and supports. J Gerontol Nurs [Internet]. 2019 Feb 1;45(2):7-13. Available from: https://pubmed.ncbi.nlm.nih.gov/30690649/ 


\section{PETRUCHA: RAPID REVIEWS IN LONG-TERM CARE}

22. Scheffelaar A, Bos N, Hendriks M, van Dulmen S, Luijkx K. Determinants of the quality of care relationships in long-term care-a systematic review. BMC Health Serv Res [Internet]. 2018 Nov 28;18(1):903. Available from: https://pubmed.ncbi. nlm.nih.gov/30486821/ Erratum in: BMC Health Serv Res. 2019 Jul 8;19(1):456.

23. Lindsey Jacobs M, Lynn Snow A, Allen RS, Hartmann CW, Dautovich N, Parmelee PA. Supporting autonomy in long-term care: lessons from nursing assistants. Geriatr Nurs [Internet]. 2019 Mar-Apr;40(2):129-37. Available from: https://pubmed. ncbi.nlm.nih.gov/30122402/

24. Bender D, Lui KYG, Holyoke P. Five opportunities for healthcare leaders to better support person- and family-centred care in long-term care settings. Healthc Manage Forum [Internet]. 2017 Jan;30(1):20-25. Available from: https://pubmed.ncbi. nlm.nih.gov/28929898/

25. Sullivan LJ, Asselin ME. Revisiting quality of life for elders in long-term care: an integrative review. Nurs Forum [Internet]. 2013 Jul-Sep;48(3):191-204. Available from: https://pubmed. ncbi.nlm.nih.gov/23889198/

26. Meehan R. Electronic health records in long-term care: staff perspectives. J Appl Gerontol [Internet]. 2017 Oct;36(10):1175-96. Available from: https://pubmed.ncbi.nlm.nih.gov/26464335/

27. Cherry BJ, Ford EW, Peterson LT. Experiences with electronic health records: early adopters in long-term care facilities. Health Care Manage Rev [Internet]. 2011 Jul-Sep;36(3):265-74. Available from: https://pubmed.ncbi.nlm.nih.gov/21646885/

28. Koopmans L, Damen N, Wagner C. Does diverse staff and skill mix of teams impact quality of care in long-term elderly health care? An exploratory case study. BMC Health Serv Res [Internet]. 2018 Dec 20;18(1):988. Available from: https:// pubmed.ncbi.nlm.nih.gov/30572880/

29. Kilpatrick K, Jabbour M, Tchouaket É, Acorn M, Donald F, Hains S. Implementing primary healthcare nurse practitioners in long-term care teams: a qualitative descriptive study. $J$ Adv Nurs [Internet]. 2019 Jun;75(6):1306-15. Available from: https://pubmed.ncbi.nlm.nih.gov/30697772

30. Colón-Emeric C, Toles M, Cary MP, et al. Sustaining complex interventions in long-term care: a qualitative study of direct care staff and managers. Implement Sci [Internet]. 2016 Jul 16;11:94. Available from: https://pubmed.ncbi.nlm.nih.gov/27422011/

31. Slaughter SE, Bampton E, Erin DF, et al. Knowledge translation interventions to sustain direct care provider behaviour change in long-term care: a process evaluation. $J$ Eval Clin Pract [Internet]. 2018 Feb;24(1):159-65. Available from: https://pubmed. ncbi.nlm.nih.gov/28691323/

32. Higuchi KS, Edwards N, Carr T, Marck P, Abdullah G. Development and evaluation of a workshop to support evidence-based practice change in long-term care. J Nurses Prof Dev [Internet]. 2015 Jan-Feb;31(1):28-34. Available from: https://pubmed. ncbi.nlm.nih.gov/25608094/

33. Kaasalainen S, Ploeg J, Donald F, et al. Positioning clinical nurse specialists and nurse practitioners as change champions to implement a pain protocol in long-term care. Pain Manag Nurs [Internet]. 2015 Apr;16(2):78-88. Available from: https:// pubmed.ncbi.nlm.nih.gov/25439111/

34. Escrig-Pinol A, Corazzini KN, Blodgett MB, Chu CH, McGilton KS. Supervisory relationships in long-term care facilities: a comparative case study of two facilities using complexity science. J Nurs Manag [Internet]. 2019 Mar;27(2):311-19. Available from: https://pubmed.ncbi.nlm.nih.gov/30203460/
35. Tyler DA, Parker VA. Staff teamwork in long-term care facilities: the influence of management style, training, and feedback. Res Gerontol Nurs [Internet]. 2011 Apr;4(2):135-46. Available from: https://pubmed.ncbi.nlm.nih.gov/20669862/

36. Baumbusch J, Phinney A. Invisible hands: the role of highly involved families in long-term residential care. J Fam Nurs [Internet]. 2014 Feb;20(1):73-97. Available from: https:// pubmed.ncbi.nlm.nih.gov/24122579/

37. Barken R, Lowndes R. Supporting family involvement in longterm residential care: promising practices for relational care. Qual Health Res [Internet]. 2018 Jan;28(1):60-72. Available from: https://pubmed.ncbi.nlm.nih.gov/28918701/

38. Martin RS, Hayes B, Gregorevic K, Lim WK. The effects of advance care planning interventions on nursing home residents: a systematic review. J Am Med Dir Assoc [Internet]. 2016 Apr;17(4):284-93. Available from: https://pubmed.ncbi.nlm. nih.gov/26861748/

39. Mignani V, Ingravallo F, Mariani E, Chattat R. Perspectives of older people living in long-term care facilities and of their family members toward advance care planning discussions: a systematic review and thematic synthesis. Clin Interv Aging [Internet]. 2017 Mar 3;12:475-84. Available from: https:// pubmed.ncbi.nlm.nih.gov/28424546/

40. Gilissen J, Pivodic L, Smets T, et al. Preconditions for successful advance care planning in nursing homes: a systematic review. Int J Nurs Stud [Internet]. 2017 Jan;66:47-59. Available from: https://pubmed.ncbi.nlm.nih.gov/27987411/

41. Petriwskyj A, Gibson A, Parker D, Banks S, Andrews S, Robinson A. A qualitative metasynthesis: family involvement in decision making for people with dementia in residential aged care. Int J Evid Based Healthc [Internet]. 2014 Jun;12(2):87-104. Available from: https://pubmed.ncbi.nlm.nih.gov/24945959/

42. Petriwskyj A, Gibson A, Parker D, Banks S, Andrews S, Robinson A. Family involvement in decision making for people with dementia in residential aged care: a systematic review of quantitative literature. Int J Evid Based Healthc [Internet]. 2014 Jun;12(2):64-86. Available from: https://pubmed.ncbi.nlm.nih. gov/24945958/

43. Ampe S, Sevenants A, Smets T, Declercq A, Van Audenhove C. Advance care planning for nursing home residents with dementia: influence of 'we DECide' on policy and practice. Patient Educ Couns [Internet]. 2017 Jan;100(1):139-46. Available from: https://pubmed.ncbi.nlm.nih.gov/27544017/

44. Flo E, Husebo BS, Bruusgaard P, et al. A review of the implementation and research strategies of advance care planning in nursing homes. BMC Geriatr [Internet]. 2016 Dec;16(1):24. Available from: https://pubmed.ncbi.nlm.nih.gov/26797091/

45. Bose-Brill S, Kretovics M, Ballenger T, et al. Testing of a tethered personal health record framework for early end-of-life discussions. Am J Manag Care [Internet]. 2016 Jul 1;22(7):9. Available from: https://pubmed.ncbi.nlm.nih.gov/27442309/

46. Fried TR, Leung SL, Blakley LA, Martino S. Development and pilot testing of a motivational interview for engagement in advance care planning. J Palliat Med [Internet]. 2018 Jul;21(7):897-98. Available from: https://pubmed.ncbi.nlm. nih.gov/29975613/

47. Rocque GB, Dionne-Odom JN, Sylvia Huang C-H, et al. Implementation and impact of patient lay navigator-led advance care planning conversations. J Pain Symptom Manage [Internet]. 2017 Apr;53(4):682-92. Available from: https://pubmed.ncbi. nlm.nih.gov/28062341/ 


\section{PETRUCHA: RAPID REVIEWS IN LONG-TERM CARE}

48. Respecting Choices [Internet]. Oregon (WI): Coalition to Transform Advanced Care (C-TAC); [cited 2021 Feb 25]. Available from: https://respectingchoices.org/

49. Levi BH, Heverley SR, Green MJ. Accuracy of a decision aid for advance care planning: simulated end-of-life decision making. J Clin Ethics [Internet]. 2011 Fall;22(3):223-38. Available from: https://pubmed.ncbi.nlm.nih.gov/22167985/

50. Quintiliani LM, Murphy JE, de la Vega PB, et al. Feasibility and patient perceptions of video declarations regarding end-oflife decisions by hospitalized patients. $J$ Palliat Med [Internet]. 2018 Jun;21(6):766-72. Available from: https://pubmed.ncbi. nlm.nih.gov/29649398/

51. Tricco AC, Antony J, Zarin W, et al. A scoping review of rapid review methods. BMC Med [Internet]. 2015 Sep 16;13:224. Available from: https://pubmed.ncbi.nlm.nih.gov/26377409/

52. Tricco AC, Langlois EV, Straus SE, editors. Rapid reviews to strengthen health policy and systems: a practical guide [Internet]. Geneva: World Health Organization; 2017 [cited 2021 Mar 21]. 142 p. Available from: https://apps.who.int/iris/bitstream/ handle/10665/258698/9789241512763-eng.pdf?sequence $=1$

53. Garritty C, Gartlehner G, Nussbaumer-Streit, et al. Cochrane Rapid Reviews Methods Group offers evidence-informed guidance to conduct rapid reviews. $J$ Clin Epidemiol [Internet]. 2021 Feb;130:13-22. Available from: https://pubmed.ncbi.nlm.nih. gov/33068715/
54. Marcella J, Kelley M. "Death is part of the job" in longterm care homes: supporting direct care staff with their grief and bereavement. Sage Open [Internet]. 2015 Mar;5(1):115. Available from: https://journals.sagepub.com/doi/ full/10.1177/2158244015573912

55. Canadian Institute for Health Information. The impact of COVID-19 on long-term care in Canada: Focus on the first 6 months [Internet]. Ottawa (ON): CIHI; 2021 [cited 2021 Jun 7]. 34 p. Available from: https://www.cihi.ca/sites/default/ files/document/impact-covid-19-long-term-care-canada-first6-months-report-en.pdf

56. Heckman GA, Kay K, Morrison A, et al. Proceedings from an international virtual townhall: Reflecting on the COVID-19 pandemic: themes from long-term care. J Am Med Dir Assoc [Internet]. 2021 Jun;22(6):1128-32. Available from: https:// pubmed.ncbi.nlm.nih.gov/33932351/

Correspondence to: Rhonda Bryce, MD, Department of Academic Family Medicine, University of Saskatchewan, West Winds Primary Health Centre, 3311 Fairlight Dr., Saskatoon, SK S7M 3 Y5

E-Mail: rhonda.bryce@usask.ca 